\title{
OS DESAFIOS DO CONHECIMENTO E O METODO DA PESQUISA
} CIENTÍFICA

Paulino José Orso

\section{RESUMO}

Este artigo trata dos desafios do conhecimento e do método da pesquisa como meios para a superação da fragmentação do saber e, conseqüentemente, para a superação da realidade.

\section{PALAVRAS-CHAVE}

Conhecimento; Método; Pesquisa.

\section{ABSTRACT}

This article refers to the challenges on knowledge and on the research method as on ways to the overcaming of the knowledge fragmentation and, consequently, for the overcoming of reality.

\section{KEY WORDS}

Knowledge; Method; Research. 
Nos meios acadêmicos, freqüentemente, ouve-se e fala-se da e sobre a inter e a transdisciplinaridade. Geralmente, tratadas numa perspectiva fenomenológica, abstrata, idealista e arbitrária, atribui-se a elas até mesmo a função de resolver problemas escolares e educacionais que não the são próprios ou, que se fazem sentir no âmbito da educação, mas que não derivam propriamente dela. Nas políticas educacionais do governo, por exemplo, são apresentadas como uma espécie de panacéia parta todos os males. Aparecem como responsáveis pela solução dos problemas educacionais, pela superação da fragmentação, pela reconstrução da unidade e organicidade do saber.

Sendo assim, necessariamente, deveriam suscitar a preocupação com a causa da fragmentação. Entretanto, a discussão sobre a divisão do saber passa longe disso; parece ocorrer numa instância etérea, como se nada tivesse a ver com as reais condições de produção e organização da vida social, com o momento histórico, com a produção da vida na sociedade capitalista, que é a responsável pela fragmentação.
Caso se intente realizar uma transformação na organização e compreensão do saber com vistas à construção da inter e da transdisciplinaridade, o diálogo, a copariticipação são condições necessárias. Contudo, não são suficientes para resolver os problemas acima mencionados.

Para discutir a questão do método da pesquisa, para evitar que se faça apenas novos arranjos e se pense que se provocou uma transformação substancial no saber, para compreender melhor os desafios, os limites e as possibilidades do método é preciso fazer uma distinção entre a realidade e as idéias ou entre a realidade e sua reprodução no plano do pensamento. Ainda que sejam interdependentes, uma não se funde na outra. Uma coisa é o ser e outra o que se diz do ser; uma coisa é a ontologia e outra a gnosiologia. Se não se coloca esta questão a tendência é tratá-las como idênticas e facilmente tende-se a autonomizar a gnosiologia face à realidade. Conseqüentemente, ao discutir a inter e a transdisciplinaridade se pode 
cai na abstração e no idealismo.

Todavia, analisando-se a realidade a partir da categoria da totalidade compreende-se que ela se constitui numa unidade (união de contrários) que se manifestada de diferentes formas. Não tem sentido discutir a realidade concreta e as idéias nem como se fossem instâncias autônomas nem como idênticas. Devido ao grau de desenvolvimento atingido pela razão e pela ciência, às vezes, tem-se a impressão de que as idéias possuem estatuto e legitimidade em si, independentes da realidade material, tal como se apresenta no idealismo. Para o idealismo as idéias põem a realidade. Ao contrário disso, na concepção materialista, as idéias têm origem e desenvolvimento no processo de produção da vida material, na ação e transformação social do homem e do meio; são sócio-históricas. Ainda que, em relação à gênese das idéias, a materialidade tenha a primazia, também não tem sentido discutir a matéria pela matéria enquanto elemento puramente precedente em relação ao homem, nem o seu oposto, as idéias enquanto absolutas. A matéria e as idéias fazem parte da totalidade do ser social do homem e exercem influência recíproca.

A realidade compreende os elementos orgânicos, inorgânicos e o ser social. Mas como é que ela se transforma em conhecimento humano? Num primeiro momento ela aparece ao homem como um todo caótico - um amontoado de seres e coisas. Porém, devido a interação com o meio, o homem vai adquirindo experiências, vai conhecendo e se apropriando das determinações. Depois as reúne novamente num todo organizado e obtém a realidade não mais como um todo informe e caótico, mas sim como uma síntese de múltiplas determinações, um todo com sentido. O homem apreende a legalidade do mundo e reconstrói no pensamento a forma do mundo, as relações sociais e o modo como os homens se organizam nele para garantir a sobrevivência. O concreto aparece como concreto pensado. As idéias, as representações, expressam a organização do mundo. A partir disso, as idéias transformam-se em mediações do homem em relação aos objetos (o mundo, o homem e as coisas) e também passam a fazer parte da síntese das múltiplas 
determinações. Mas, a idealização - a transformação do objeto em idéia -, a representação, não é a mesma coisa que o objeto idealizado e representado. Relaciona-se com ele, mas não se funde, não se identifica com ele.

A razão de ser e de discutir tanto a realidade material quanto as idéias e o conhecimento é o homem. Quando se coloca a questão do homem na história, não é mais possível discutir em termos de autonomia da matéria (materialismo ingênuo) nem das idéias (idealismo puro). Compreende-se o homem enquanto determinado e determinante social, um mediador entre a realidade e as idéias, compreendidas como unidade.

O homem, enquanto ser histórico é produto do meio e faz parte dele. $\mathrm{O}$ incessante movimento da matéria o produziu como homem, diferente dos demais seres. Através da constante ação do meio sobre os hominídeas ocorreu um processo de transformação que levou à produção do homem enquanto um ser diferenciado. A própria razão constitui-se num produto desse processo. Enquanto o homem é transformado e se transforma, também desenvolve seu cérebro.
Num primeiro momento o homem, como nos diz Alvaro Vieira Pinto, é um produzido pelo produzido pela natureza. Porém, de um produzido pelo produzido pela natureza passa a ser produtor das condições que o produz ${ }^{\mathbb{1}}$. Isto significa que não dá para pensar o meio sem o homem, nem este sem aquele.No seu processo de desenvolvimento, inicialmente, as idéias tinham e dependiam de uma relação direta entre a forma e o conteúdo, entre o objeto e a representação - consciência é consciência do objeto, corresponde ao seu processo de vida social imediata - a idéia de peixe está ligada diretamente ao peixe; a idéia de perigo está vinculada ao perigo imediatamente presenciado. Porém, com o processo de transformação o homem adquire a capacidade de desvincular as idéias dos objetos imediatos, torna possível sua representação no plano das idéias e pode libertar as idéias das amarras dos objetos. Isto significa um salto de qualidade, pois, o homem adquiriu a capacidade de fazer ciência e de fazer desta um instrumento de ação

\footnotetext{
${ }^{1}$ Cf. PINTO, Alvaro Vieira. Ciência e existência. 3. ed. Rio de Janeiro: Paz e Terra, 1979. p. 85.
} 
intencional sobre o mundo; adquiriu a capacidade de transformar intencionalmente o mundo. Mas, há uma complicação, pois, no "mundo das idéias", à medida em que elas se libertam

do mundo, pode se supervalorizar a forma em detrimento do conteúdo, autonomizar a gnosiologia face a ontologia e cair no idealismo. Nessa perspectiva, contanto que não haja contradição nos termos, tudo se justifica.

Por isso, ainda que as idéias possam adquirir uma autonomia relativa, não podemos esquecer que elas têm seu fundamento na materialidade. Como tais, tornam-se instrumentos que, a partir das representações, das aparências, possibilitam a busca da essência - a compreensão do ser social -, pois não são idênticas. Como diz Marx, "Se essência e aparência fossem a mesma coisa, seria inútil toda a ciência".

Se a essência e a aparência, se o ser e o conhecer, se a coisa e o que se diz da coisa, se a realidade e a representação, se a ontologia e gnosiologia são "coisas" distintas, não significa que sejam absolutas, autônomas e independentes uma em reação à outra. No âmbito do conhecimento, a questão fundamental é: como fazer para que a aparência que se capta (o que se diz da coisa, o que se diz do ser), as representações, expressem e manifestem no plano do pensamento o mais fielmente possível a essência, o ser, a coisa, a realidade, a ontologia? $\mathrm{O}$ problema se resolve no plano do ser ou das idéias? Pode-se dizer que em nenhum dos dois absolutizados. É no homem que se coloca a questão e não no "mundo das idéias", nem no dos entes; no homem enquanto ser situado, em sua relação no e com o mundo, como um ser que é, simultaneamente, sujeito e objeto, compreendidos como unidade indissolúvel. Se afirmarmos o domínio de um ou de outro cairemos no objetivismo ou, no seu oposto, no subjetivismo que, quando absolutizados e compreendidos de forma reducionista tornam-se equívocos gnosiológicos. $\mathrm{O}$ conhecimento objetivo envolve sujeito e objeto. Se não forem compreendidos como um objeto único, pertencentes à totalidade do ser social, no máximo a que se chega é na compreensão 
de conhecimento enquanto relação ${ }^{2} \mathrm{e}$, desta forma, estaremos, mesmo inintencionalmente, afirmando o dualismo cognitivo, que contribuem para a fragmentação gnosiológica.

A objetividade, assim concebida, supõe a possibilidade de o homem conhecer efetivamente a realidade, ao contrário do que afirma Kant, os neokantianos e os irracionalistas, por exemplo, que defendem a impossibilidade de conhecer tanto o sujeito quanto o objeto para além das aparências, de conhecer as essências. Esta posição é compartilhada pelos pósmodernos ${ }^{3}$, derivando no relativismo. Para eles só é possível conhecer os fenômenos.

$\mathrm{Na}$ perspectiva idealista hegeliana o real e o ideal tornam-se idênticos, confundemse. "O real é o ideal e o ideal é o real" Não há distinção entre a coisa e o que se diz dela, entre a ontologia e a gnosiologia, entre o ser e as representações, entre a

${ }^{2}$ Cf. SCHAFF, Adam. História e verdade. São Paulo: Martins Fontes, 1978.

${ }^{3}$ Cf. WOOD, Ellen Meiksins ; FOSTER, John Bellamy (Org.). Em defesa da história: marxismo e pós-modernidade. Rio de Janeiro: Jorge Zahar Editor, 1999.

${ }^{4}$ Cf. MARX, Karl. Crítica da filosofia do direito de Hegel. 2. ed. Livraria Martins Fontes, [s.d.]. essência e a aparência. Este idealismo provoca uma série de consequiências. A partir dele ocorre a absolutização e onipotência das idéias, a crença no poder ilimitado da razão e do homem; aparência e essência se confundem; dispensa-se a ciência enquanto instrumento de conhecimento, de ação e de transformação. Nesta perspectiva, se há identidade, a superação de uma, ocorre pela sobreposição de outra. Dispensam-se as mediações. O desenvolvimento seria linear. A fragmentação do saber, por sua vez, simplesmente, seria superada através de uma re-articulação entre as disciplinas e não pela superação da realidade que a produz.

Transformados os problemas reais em ideais e, elevados à categoria de absolutos resolvem-se (os problemas) no plano das idéias. De acordo com os neopositivistas ou positivistas lógicos, eles seriam resolvidos através da interpretação das idéias - uma questão de linguagem -, da depuração das imprecisões, dos inconvenientes, das antinomias. Desta orientação conclui-se que através da análise da linguagem poder-se-ia resolver todos o problemas. A diferença ente os 
positivistas e os neopositivistas é que os primeiros se apoiam em razões científicas e gnosiológicas e os segundos em razões semânticas. Nesta perspectiva Habermas propõe a resolução do impasse através da teoria do Agir Comunicativo ou da Razão Comunicativa. Porém, tanto este como os neopositivistas, de certa forma, caem no idealismo.

Marx, ao tratar do método de conhecimento, contrapõe-se ao idealismo dizendo que

[...] as determinações abstratas conduzem à reprodução do concreto por meio do pensamento. Por isso é que Hegel caiu na ilusão de conceber o real como resultado do pensamento que se sintetiza em si, se aprofunda em si, e se move por si: enquanto que o método que consiste em elevar-se do abstrato ao concreto não é senão a maneira de proceder do pensamento para se apropriar do concreto, para reproduzi-lo como concreto pensado 5 .

Marx supera o idealismo, a falsa identidade entre real e ideal e revela que a realidade não se reduz às idéias; estas são expressões daquela, são instrumentos para a apropriação e reconstrução dos objetos

\footnotetext{
${ }^{5}$ MARX, K. Para a Crítica da Economia Política. In. OS PENSADORES. 5.ed. São Paulo: Nova Cultural, 1991. p.17.
}

enquanto pensamento, enquanto conhecimento.

Se as idéias têm a ver com a base material, se enquanto conhecimento, compreensão e explicitação da existência e da produção social as idéias representam aquilo que as possibilita, que lhe dão existência, é um equívoco pensálas dissociadas da prática social. Portanto, as formas de organização do conhecimento e do saber têm a ver com o ser social de cada época, de cada sociedade e de cada contexto social. Assim, se a realidade se apresenta cindida em sua base material o conhecimento também aparece fragmentado ou, dito de outra forma, a fragmentação do conhecimento ocorre em função da cisão na base material da sociedade. A organização do conhecimento baseado nas disciplinas expressam essa realidade dividida. Portanto, a superação da fragmentação não ocorre apenas com um re-arranjo nas idéias, com uma rearticulação entre os saberes.

Comumente, atribui-se a superação da fragmentação do saber à inter e à transdisciplinaridade, duas formas de 
relação entre as disciplinas. Mas vejamos:

Quando começa a fragmentação do saber? Começa com o surgimento da propriedade privada, com o surgimento das classes sociais, com a divisão social do trabalho, com a alienação, com a divisão entre os que pensam e os que fazem, com a divisão entre trabalho manual e intelectual e se aprofunda com positivismo, com o desenvolvimento da sociedade capitalista e com a divisão entre capital e trabalho, que reforça a divisão entre os que pensam e os que executam o trabalho e aprofunda a alienação. Ou seja, a divisão e a fragmentação do saber tem a ver diretamente com a forma de organização social, com a forma de produção da vida material fundada na divisão de classes. Frigotto enfatiza que

a cisão que se produz e desenvolve no plano das relações de produção do homem social, enquanto uma totalidade concreta, explicita-se necessariamente no plano da consciência, das representações e concepções da realidade ${ }^{6}$.

\footnotetext{
${ }^{6}$ FRIGOTTO, G. A Interdisciplinaridade como necessidade e problema nas ciências sociais (texto). p. 35 .
}

Como já dissemos acima, as idéias e as concepções não têm vida própria. Elas expressam o momento histórico e a forma de organização do modo de produzir a vida material do homem em cada momento. A cisão que está presente no plano das relações sociais de produção, reproduz-se no plano do pensamento e das representações.

Quando não existiam classes sociais o conhecimento e o saber ocorriam pela vida e estavam voltados à vida. Não havia necessidade de privar ninguém de qualquer informação e experiência, não havia fragmentação. A socialização dos conhecimentos significava melhor nível de vida para o grupo. Havia unidade entre o saber e vida e o homem ocupava o lugar central.

Quando surge a sociedade de classes o homem deixa de ser o centro e a qualidade do conhecimento e da sobrevivência passa a depender da posição social que a pessoa ocupa na divisão social do trabalho. Nela, uns são instrumentalizados à produção e outros ao controle desta e dos meios de produção. Assim, fragmenta-se a produção, o 
conhecimento e o homem. Os que produzem não usufruem nem se reconhecem na produção. $\mathrm{O}$ conhecimento deixa de ser concebido como uma necessidade de socialização e passa a ser instrumento de controle, de poder e de lucro, isto é, seguindo a lógica do modo de produção, o conhecimento também é privatizado, mistificado e individualizado.

Devido à da divisão da sociedade em classes, a classe enconomicamente dominante detém também o poder ideológico. "As idéias dominantes numa determinada época, são as idéias dos dominantes", diz Marx. A divisão do saber contribui para a manutenção e reprodução da dominação. Por isso, a classe dominante e seus ideólogos fazem o possível para apresentar o "ideal e real" como idênticos e manter as discussões no "plano das idéias". Assim, mistificam as representações e auxiliam na reprodução do status quo.

Se a realidade se apresenta cindida na base material, a superação de um determinado tipo de conhecimento, a superação da fragmentação não ocorre apenas através da mudança da mentalidade ou de uma nova articulação do saber. Mas sim com a mudança no modo de organizar a produção material da vida social. Isto, produz uma conseqüente mudança no conteúdo das representações.

O positivismo, ao invés de se preocupar em alterar a ordem social, apresenta-se como a justificação da mesma. Concebe o mundo, a realidade, o conhecimento como um conjunto de partes justapostas, articuladas entre si, formando um sistema. Umas são concebidas como mais e outras menos importantes, formando uma hierarquia. Marcada pelo positivismo a ciência organiza o conhecimento por áreas e disciplinas. As diversas áreas e disciplinas, justapostas e unidas entre si formam o sistema do saber, o sistema educacional, o sistema de ensino - um todo articulado, harmônico e funcional.

A disciplinaridade apresenta-se como uma forma específica de tratar os conteúdos do conhecimento, a ciência e a realidade, própria da concepção de mundo positivista e adequada ao modo de produzir a vida na sociedade capitalista. A divisão do saber, a disciplinaridade é 
reflexo da cisão que ocorre no modo de produzir a vida social, que é justificada em função de facilitar a especialização, mas que, devido aos condicionantes materiais, acaba reforçando a fragmentação e a mistificação do saber,

Mantendo a preocupação no "plano das idéias", os ideólogos da classe dominante atribuem à inter e à transdisciplinaridade a "missão" de superar o problema da fragmentação do saber. Porém, será possível dar conta desta tarefa? Elas não se constituem em formas de abordar o conhecimento também de forma fragmentada? Será que a fragmentação do saber pode ser superada sem que se supere a realidade que a produz? As disciplinas, a multi, a pluri, a inter e a transdisciplinaridade se propõem a transformar e superar o modo de produção da vida material ou contribuem para reforçá-lo ainda mais?

Até algum tempo atrás não havia a preocupação nem se falava em transdisciplinaridade. Atribuía-se à interdisciplinaridade a superação da fragmentação explicidada na disciplinaridade. Porém, revelada a impossibilidade de tal empreitada e desgastada esta forma, criou-se um novo artifício - a transdisciplinaridade - que muda a apararência, mas mantém a essência.

A disciplinaridade é uma forma de tratar o saber e a realidade por campos e áreas de saber delimitadas; a multidisciplinaridade a a pluridisciplinaridade aglutinam as disciplinas, mas continuam mantendo a justaposição e a fragmentação entre as mesmas. Tratadas como partes justapostas, colocadas umas junto às outras, a totalidade resume-se à integração e junção do conjunto das partes (disciplinas). Estas técnicas positivistas - concebem as disciplinas como campos de saber estanques, separados e incomunicáveis. Já, a transdisciplinaridade parte do princípio da disciplinaridade, mas propõe uma certa abertura e interpenetração de uma disciplina em relação a outra. Trans é um vocábulo latino que significa "movimento para além de", "através de", "posição para além de". Assim, transdisciplinaridade significa movimento entre, através das disciplinas. Contudo, 
também continua mantendo as disciplinas, ainda que abra espaço para um certo trânsito entre elas.

Mais do que um mecanismo e uma forma a inter e a transdisciplinaridade deveriam constituir-se em processos, em praxis pedagógicas, que ao mesmo tempo articulam as disciplinas na busca da unidade e atuam sobre a realidade tendo em vistas à sua superação - condição sine qua non à superação da fragmentação do saber e à compreensão do conhecimento como síntese de múltiplas determinações - unidade de contrários. Dessa forma, a inter e a transdisciplinaridade constituirse-iam num método teórico-prático. Caso elas não sejam a expressão da superação prática da fragmentação da realidade, a articulação entre as disciplinas passará de uma "nova" forma de articulação entre disciplinas diferentes, de uma unidade artificial e abstrata? Não perpetuará a fragmentação do conhecimento? Pois, como diz Marx, uma filosofia não é superada até que a realidade que a produziu também não for superada.

O equívoco não está em organizar o conhecimento de forma diferente. Mas sim em pensar que, assim procedendo, é suficiente para resolver o problema da fragmentação do saber. A resolução é uma questão teórico-prática. Como afirma Marx "todos os mistérios que levam a teoria ao misticismo encontram a sua solução racional na práxis humana e no compreender desta práxis",

A inter e a transdisciplinaridade supõem movimento entre as disciplinas. Mas, também partem do princípio disciplinar. A base está nas disciplinas. Portanto, se ocorrer o fechamento nelas, mesmo que haja um movimento entre elas, não alterará a fragmentação do saber. Somente a construção de um projeto teórico-prático que tenha como meta a superação dessa realidade social poderá ir criando as condições para a construção de uma efetiva inter e transdisciplinaridade, que possibilitem a reconstrução da realidade no plano do pensamento, numa perspectiva unitária e de totalidade. Elas devem fazer parte de uma concepção de mundo, de um projeto. Um projeto que, tendo como meta a superação da realidade, reverta numa nova

\footnotetext{
${ }^{7}$ MARX, K. Tese sobre Feuerbach. In: ideologia alemã. Lisboa: Avante, p. 105.
} . A 
compreensão do saber e numa rearticulação das disciplinas, direcionada à uma ação transformadora. Assim, enquanto métodos elas podem contribuir para a reconstrução da unidade e da totalidade. Esta não é sinônimo de um conjunto de disciplinas, ciências, áreas de conhecimento ou conjunto de partes justapostas. A totalidade é sempre uma busca, um projeto inacabado, um projeto por fazer-se. E a inter e a transdisciplinaridade podem se constituir em mediações para, no plano teórico, desvelar as razões e as raízes da fragmentação e de revelar seus próprios limites em se tratando de superá-los, para reconstituir a unidade da ciência no plano das idéias e contribuir para a transformação da realidade sócio-cultural. Para que isso ocorra não basta apenas o diálogo, a intersubjetividade, a ação comunicativa, a abertura em relação as disciplinas, a justaposição do conhecimento. É preciso que a busca do conhecimento e a pesquisa científica estejam articuladas a uma concepção de mundo que objetive a superação do atual modo de produção.

Então, onde e como a inter e a transdisciplinaridade devem ser tratadas?

Como uma questão de forma? Não. Álvaro Vieira Pinto afirma que é:

necessário compreender que forma e conteúdo são apenas aspectos distintos, mas unidos - de uma mesma realidade ... um todo, concretamente indivisível e só analiticamente separável em partes. Por isso, estão inter-relacionados e se condicionam um ao outro. São aspectos $e^{\mathrm{e}}$ não componentes autônomos ${ }^{8}$.

Não existe forma sem conteúdo nem conteúdo sem forma. Não se constrói uma efetiva inter nem uma transdisciplinaridade se apenas se fizer um re-arranjo na forma de tratar o conhecimento. É preciso que conteúdo e forma, indissociados, expressem esta unidade concreta. Restabelecer a unidade na modalidade de conhecimento, eis o desafio, pois, pressupõe uma nova modalidade de produzir a vida social. $\mathrm{Ou}$ seja, a superação da fragmentação ocorre à medida que vai ocorrendo a transformação da realidade. Com as mudanças na base material também vão surgindo novas formas de organização do conhecimento.

\footnotetext{
${ }^{8}$ PINTO, A.V. Sete lições sobre educação de adultos. 9. ed. São Paulo: Cortez, 1994. p.44-45.
} 
Muitas vezes justifica-se a impossibilidade de superar a fragmentação do saber em função da impossibilidade de se abarcar todo o real. É claro que ninguém, nenhuma teoria, disciplina ou área do saber é capaz de dar conta da totalidade do real, que é sempre maior, mais complexo, mais amplo do que a capacidade de compreendê-lo e explicá-lo nas suas múltiplas determinações. É preciso reconhecer os limites. Porém, se fosse este o impedimento, o problema seria insolúvel. No entanto, ele não está na limitação das pessoas, das teorias, das disciplinas ou das ciências em abarcar a totalidade do real através do saber. Está na organização social que impede que o homem se compreenda na relação particular/universal, na absolutização das partes, na autonomização e na independência com que cada um dos elementos é concebido e tratado na relação com os demais, na confusão entre aparência e essência; está, fundamentalmente, no modo de produção que produz a alienação.

O conhecimento pressupõe humildade. À medida que houver humildade, que cada um deixar de aparentar que é absoluto e demonstrar que depende e necessita dos outros, é possível caminhar rumo à superação da realidade e, conseqüentemente, da fragmentação do saber. Isso também ocorrerá à medida que as forças produtivas forem sendo alteradas, superadas por novas e provocarem mudanças nas relações de produção.

A necessidade de construirmos um novo modo de organização social, uma nova realidade e também uma nova forma de organização do conhecimento não se deve apenas ao fato de sermos criativos e de mostrarmos que podemos fazer diferentes arranjos segundo a capacidade e o momento que vivemos. Essa mudança é necessária principalmente devido às conseqüências que as atuais formas de organização provocam no homem e na sociedade.

A inter e a transdisciplinaridade podem contribuir para a superação da fragmentação do conhecimento, para a compreensão da realidade para além das aparências, para a reconstrução do real enquanto síntese de múltiplas 
determinações, como concreto pensado, contanto que se coloque a possibilidade de superação da atual forma de organização social da produção da vida material.

Para o positivismo e para o capitalismo não está colocada a necessidade de outro projeto social. A organização do conhecimento de forma fragmentada corresponde à sua própria "natureza" desse modo de produção e dessa necessidade de reprodução. Portanto, a superação da fragmentação do conhecimento, do homem e da realidade somente poderá ser proposta por um projeto social diferente que tenha como objetivo o fim da alienação e da dominação humanas.

Neste sentido, o conhecimento e o método da pesquisa constituem-se num contínuo desafio. 


\section{REFERÊNCIAS}

FRIGOTTO, Gaudêncio. A interdisciplinaridade como necessidade e problema nas ciências sociais. [S.n.t.].

KANT, Emmanuel. Crítica da Razão Pura. Trad. Valério Rohden e Udo B. Moosburger. 4. ed. São Paulo: Nova Cultural, 1991. (Os Pensadores).

MARX, Karl. Crítica da filosofia do direito de Hegel. 2. ed. Livraria Martins Fontes, [s.d.].

- Para a Crítica da Economia Política. In. OS PENSADORES. Trad. José Carlos Bruni [et al.]. 5. ed. São Paulo: Nova Cultural, 1991.

Avante, [s.d.].

A ideologia alemã. Lisboa:

PINTO, Alvaro Vieira. Ciência e existência. 3. ed. Rio de Janeiro: Paz e Terra, 1979.

. Sete lições sobre educação de adultos. 9. ed. São Paulo: Cortez, 1994.

SCHAFF, Adam. História e verdade. São Paulo: Martins Fontes, 1978.

PAULINO JOSÉ ORSO

Docente da Unioeste

WOOD, Ellen Meiksins ; FOSTER, John Bellamy (Org.). Em defesa da história: marxismo e pós-modernidade. Rio de Janeiro: Jorge Zahar Editor, 1999.

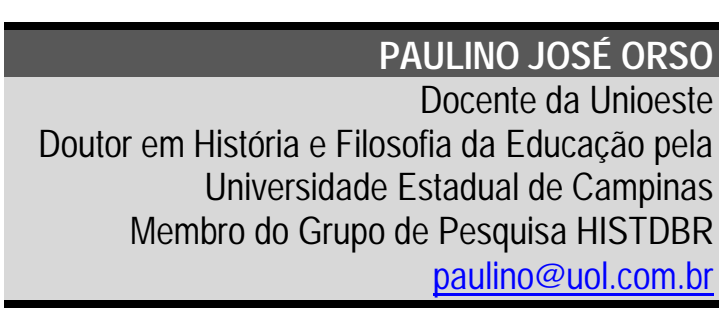

Aceito para publicação em: 30/11/2003

(c) ETD - Educação Temática Digital, Campinas, v.5, n.1, p.25-39, dez. 2003 - ISSN: 1517-2539. 